\title{
Risk of conventional cardiac surgery among patients with severe left ventricular dysfunction in the era of mechanical circulatory support
}

Nassir M. Thalji, MBChB, PhD, ${ }^{a}$ Simon Maltais, MD, PhD, ${ }^{a}$ Richard C. Daly, MD,

Kevin L. Greason, MD, ${ }^{a}$ Hartzell V. Schaff, MD, ${ }^{a}$ Shannon M. Dunlay, MD, MS, ${ }^{b}$ and John M. Stulak, MD ${ }^{a}$

\section{ABSTRACT}

Background: Despite suggestions that severe left ventricle dysfunction may warrant selection of durable mechanical circulatory support over conventional surgery, comparative studies are lacking due to incomplete characterization of patients at highest risk after conventional surgery. We sought to define subsets of patients with severe left ventricle dysfunction who are at greatest mortality risk following conventional cardiac surgery.

Methods: We studied 892 patients aged $\geq 18$ years who underwent conventional coronary or valve surgery from 1993 to 2014, with preoperative ejection fraction $\leq 25 \%$. Exclusions were transcatheter interventions, major concomitant procedures, active endocarditis, and prior/concurrent durable mechanical circulatory support use. Logistic and Cox regression identified determinants of early and late mortality.

Results: Median age was 70 years (interquartile range, 62-76 years), 46\% $(\mathrm{n}=411)$ had New York Heart Association (NYHA) functional class IV symptoms, and 16\% $(\mathrm{n}=142)$ had undergone prior surgery. Operative mortality was $7.5 \%$. NYHA functional class IV (odds ratio [OR], $1.88 ; P=.033$ ), prior cardiac surgery (OR, 2.13; $P=.017)$, peripheral vascular disease (OR, 2.55; $P=.001)$, emergency status (OR, 2.68; $P=.024)$, and intra-aortic balloon pump use $(\mathrm{OR}, 4.95 ; P<.001)$ independently predicted operative death. Risk imparted by presence of both NYHA functional class IV symptoms and prior surgery was additive, with a 4-fold increase in early mortality risk (OR, 3.95; $P=.003)$. Prior surgery increased the hazard of late death by $60 \%(P<.001)$. In patients without prior surgery, late mortality was greatest in those aged $\geq 70$ years (hazard ratio, $1.86 ; P<.001)$, especially if NYHA functional class IV symptoms were concurrently present (hazard ratio, $2.25 ; P<.001$ ). Surgery type (coronary artery bypass graft surgery, aortic valve surgery, or mitral valve surgery) did not predict long-term outcome.

Conclusions: In patients referred for conventional surgery with an ejection fraction $\leq 25 \%$, prior cardiac surgery, and/or NYHA functional class IV symptoms-particularly in those aged $\geq 70$ years-confer significant and sustained survival disadvantages. Such high-risk subsets may benefit from durable mechanical circulatory support consideration. (J Thorac Cardiovasc Surg 2018;156:1530-40)

From the Departments of ${ }^{\mathrm{a} C}$ Cardiovascular Surgery and ${ }^{\mathrm{b}}$ Cardiovascular Diseases, Mayo Clinic College of Medicine, Rochester, Minn.

Supported by the Department of Cardiovascular Surgery, Mayo Clinic, Rochester, Minn.

Read at the 97th Annual Meeting of The American Association for Thoracic Surgery, Boston, Massachusetts, April 29-May 3, 2017.

Received for publication April 30, 2017; revisions received Feb 25, 2018; accepted for publication April 11, 2018.

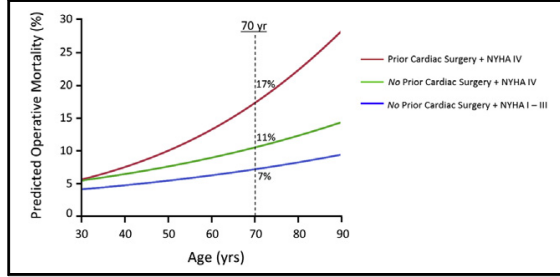

Probability of operative death with $\mathrm{EF} \leq 25 \%$ by age, prior surgery, and NYHA functional class.

\section{Central Message}

With $\mathrm{EF} \leq 25 \%$, mortality after conventional surgery is greatest in patients with prior surgery, NYHA functional class IV symptoms, and age $\geq 70$ years. Such patients may benefit from durable MCS consideration.

\section{Perspective}

Despite suggestions that severe LV dysfunction may warrant durable MCS selection over conventional surgery, comparative studies are lacking due to incomplete characterization of patients at highest risk after conventional surgery. With $\mathrm{EF} \leq 25 \%$, mortality after conventional surgery is greatest in those patients with prior cardiac surgery and NYHA functional class IV symptoms, especially if the patient is aged $\geq 70$ years.

See Editorial Commentary page 1541

See Editorial page 1527.
Address for reprints: John M. Stulak, MD, Department of Cardiovascular Surgery, Mayo Clinic College of Medicine; 200 First St, SW, Rochester, MN 55905 (E-mail: stulak.john@mayo.edu). $0022-5223 / \$ 36.00$

Copyright (c) 2018 by The American Association for Thoracic Surgery https://doi.org/10.1016/j.jtcvs.2018.04.130 


\section{Abbreviations and Acronyms \\ $\mathrm{CABG}=$ coronary artery bypass grafting \\ $\mathrm{EF} \quad=$ ejection fraction \\ IABP = intra-aortic balloon pump \\ INTERMACS $=$ Interagency Registry for \\ Mechanically Assisted Circulatory \\ Support \\ $\mathrm{LV} \quad=$ left ventricle \\ LVAD = left ventricular assist device \\ MCS $=$ mechanical circulatory support \\ NYHA $=$ New York Heart Association \\ PVD $\quad=$ peripheral vascular disease}

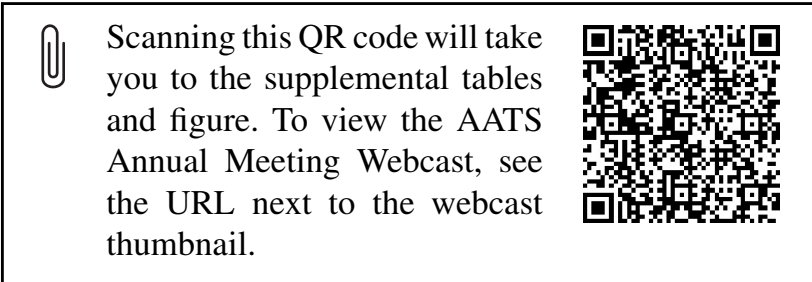

More than 250,000 adult cardiac surgeries are performed annually in the United States, ${ }^{1}$ with preoperative left ventricle (LV) dysfunction affecting between $3 \%$ and $18 \%$ of patients. ${ }^{2-4}$ Ventricle dysfunction-often manifesting as depressed $\mathrm{LV}$ ejection fraction (EF)—is an independent determinant of poor operative outcomes. ${ }^{2,5,6}$ Guidelines therefore advocate strongly in favor of operative intervention before onset of LV dysfunction in those with coronary artery or valve disease. ${ }^{7,8}$ Even if LV impairment has already developed, patient survival and quality of life following coronary or valve surgery remain superior to medical management. ${ }^{3,5,9-16}$ With prevalence of LV impairment projected to climb, ${ }^{2}$ cardiac surgeons are increasingly facing the challenge of managing patients at very high surgical risk, many being referred for operative intervention as a last resort.

With emergence of durable mechanical circulatory support (MCS) as a long-term option for end-stage heart failure, ${ }^{17,18}$ it has been proposed that this platform may serve as an alternative approach in managing patients with severe LV dysfunction and coexistent coronary and/or valve disease. ${ }^{19}$ Durable MCS strategies such as LV assist devices (LVADs) are not without substantial potential risk and are not to be trivialized in their consideration as therapeutic substitutes. ${ }^{20-22}$ To date, there remains a paucity of literature directly comparing conventional surgery versus durable MCS for patients with coronary or valve disease and concurrent severe LV impairment. Patient selection and candidacy for such comparative effectiveness studies is hindered at least in part by incomplete characterization of which patients are at greatest operative risk after conventional surgery, and hence may potentially benefit most from a durable MCS strategy. Thus, in the current study we evaluated patients with severe LV impairmentdefined as $\mathrm{EF} \leq 25 \%$-who underwent conventional coronary and/or valve surgery. We sought to delineate early and late mortality rates in this challenging population, and ultimately to define categories of patients at greatest mortality risk.

\section{METHODS}

\section{Study Design and Subjects}

We retrospectively evaluated adult patients aged $\geq 18$ years undergoing coronary artery bypass grafting $(\mathrm{CABG})$ surgery, conventional aortic valve surgery, and/or mitral valve surgery at our institution from January 1993 to July 2014. We studied only those with preoperative EF $\leq 25 \%$. This threshold was chosen because it is a criterion for consideration of durable MCS referral. ${ }^{23,24}$ Exclusions were active endocarditis, transcatheter valve interventions, previous or concurrent VAD implantation, and major concomitant procedures per the Society of Thoracic Surgeons definitions (eg, thoracic aortic repair/replacement, septal myectomy, and maze procedure). Overall, 892 patients met enrollment criteria (Figure 1). All subjects provided informed consent. Mayo Clinic Institutional Review Board approved this investigation.

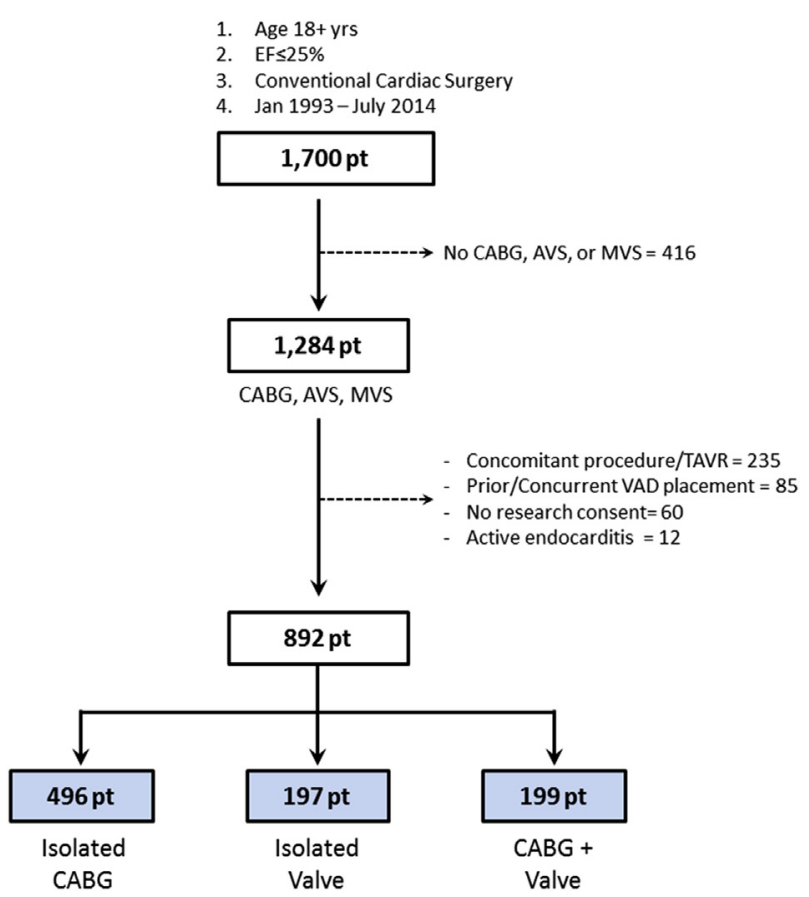

FIGURE 1. Identification of study subjects. $E F$, Ejection fraction; $C A B G$, coronary artery bypass grafting; $A V S$, aortic valve surgery; $M V S$, mitral valve surgery; TAVR, transcatheter aortic valve replacement. 


\section{Clinical Data}

Patients were identified from the Department of Cardiovascular Surgery patient database. Data, including demographic characteristics, symptoms, comorbidities, surgery-specific variables, and perioperative outcomes were abstracted from the Department of Cardiovascular Surgery electronic database and by manual medical record review. Preoperative echocardiographic measurement of EF was available from the Department of Cardiovascular Diseases echocardiography database. Variable definitions were in alignment with the Society of Thoracic Surgeons national database. ${ }^{25}$ Follow-up was from medical records, postal questionnaires, the electronic Accurint database (www.Accurint.com), and review of death certificates. End points were early operative mortality, defined as intraoperative death, death before hospital dismissal, or within 30 days of surgery, and late all-cause mortality, defined as death $>30$ days following surgery.

\section{Statistical Analysis}

Continuous variables are summarized as means \pm standard deviation or medians (inter-quartile range [IQR]). The Shapiro-Wilk test was used to test for normality of distribution. Categorical variables are reported as frequencies (percentages). One-way analysis of variance was used to compare continuous data among 3 groups. The Cochrane-Armitage test was used to evaluate for trends across 3 groups.

Logistic regression methods identified predictors of early operative mortality. Covariates considered for modeling were limited a priori to pre- and intraoperative variables. The variable intra-aortic balloon pump (IABP) use was a composite of pre- and intraoperative use. Multivariable logistic regression models were constructed by considering covariates meeting the threshold of statistical significance, defined as $P<.05$, in univariate analysis, and covariates deemed to be clinically important based on peer-reviewed literature and consensus of expert surgeons (eg, age). To avoid overfitting models were limited to 6 variables (1 variable per 10 events). The final model was that with the greatest discriminatory power (C-index).

Again using logistic regression methods, operative mortality was modeled as a function of age, for subsets of patients with no prior cardiac surgery + New York Heart Association (NYHA) functional class I through III symptoms, no prior cardiac surgery + NYHA functional class IV symptoms, and prior cardiac surgery + NYHA functional class IV symptoms. Resultant regression equations were used to simulate 5000 hypothetical, random outputs that were plotted graphically to depict the influence of age as a continuous variable on the predicted probability of operative mortality. The large number of outputs contributed a smoothing effect.

Late follow-up was from surgical date until death or last known followup. Kaplan-Meier methods were used to estimate survival, with patients censored at last follow-up. The log-rank test compared survival between subsets categorized based on history of prior cardiac surgery, age, or NYHA classification. Univariate and multivariate predictors of long-term mortality were determined using Cox proportional hazards models. Variables considered for multivariable model construction were those achieving univariate statistical significance, or if they were considered clinically relevant (eg, age). In subgroup analysis, Cox models were constructed to determine predictors of late death among patients without a history of prior cardiac surgery. Using these models, age was then considered as a categorical, binary variable to identify an age threshold associated with greatest late mortality risk. Multiple ages were evaluated sequentially, with the final age cutpoint having the greatest hazard ratio (HR) and narrowest confidence interval (CI). In secondary analysis, multivariable models were generated with surgical era and surgery type (ie, CABG, aortic valve surgery, and mitral valve surgery) forced in as covariates.

Statistical tests were 2-sided with an alpha of 0.05 for statistical significance. Analyses were performed using SAS 9.3 software (SAS institute Inc, Cary, NC).
TABLE 1. Baseline characteristics of the study cohort

\begin{tabular}{|c|c|}
\hline Variable & Total $(\mathbf{N}=\mathbf{8 9 2})$ \\
\hline Age $(y)$ & $70(62-76)$ \\
\hline Male sex & $716(80)$ \\
\hline $\begin{array}{l}\text { New York Heart Association functional class } \\
\text { I } \\
\text { II } \\
\text { III } \\
\text { IV }\end{array}$ & $\begin{array}{r}19(2) \\
97(11) \\
363(41) \\
413(46)\end{array}$ \\
\hline Congestive heart failure & $571(64)$ \\
\hline Cerebrovascular accident & $157(17)$ \\
\hline Diabetes mellitus & $323(36)$ \\
\hline Hypercholesterolemia & $642(72)$ \\
\hline Family history of coronary artery disease & $285(33)$ \\
\hline Hypertension & $624(70)$ \\
\hline Prior myocardial infarction & $492(55)$ \\
\hline Obese, defined as body mass index $\geq 30$ & $279(31)$ \\
\hline Peripheral vascular disease & $218(25)$ \\
\hline Smoker & $583(66)$ \\
\hline Chronic lung disease & $206(23)$ \\
\hline Prior cardiac surgery & $142(16)$ \\
\hline Previous coronary artery bypass graft surgery & $114(13)$ \\
\hline Previous valve surgery & $51(6)$ \\
\hline Ejection fraction $(\%)$ & $23(21-25)$ \\
\hline Left main artery disease & $237(34.1)$ \\
\hline $\begin{array}{l}\text { Aortic valve disease* } \\
\text { Stenosis } \\
\text { Insufficiency } \\
\text { Mixed }\end{array}$ & $\begin{array}{c}237(82) \\
40(14) \\
12(4)\end{array}$ \\
\hline $\begin{array}{l}\text { Mitral valve disease } \dagger \\
\text { Stenosis } \\
\text { Regurgitation } \\
\text { Mixed }\end{array}$ & $\begin{array}{r}16(12) \\
113(85) \\
4(3)\end{array}$ \\
\hline Society of Thoracic Surgeons risk score $(\%)$ & $5.1(2.4-9.0)$ \\
\hline
\end{tabular}

Values are presented as median (interquartile range) or $\mathrm{n}(\%)$. *Percentages are from a denominator of 289 patients who underwent aortic valve surgery. $\dagger$ Percentages are from a denominator of 133 patients who underwent mitral valve surgery.

\section{RESULTS}

\section{Baseline Clinical and Operative Characteristics}

Baseline characteristics of the 892 study patients are outlined in Table 1 . Median age was 70 years (IQR, 6276 years $)$, and $80 \%(n=716)$ were men. A total of $16 \%$ $(n=142)$ had prior cardiac surgery. Prior CABG was performed in 114 patients, and valve surgery was performed in 51 patients, with some patients undergoing 2 previous surgeries. NYHA functional class IV symptoms were present in $46 \%$ of patients $(n=411)$. Median EF was $23 \%$ (IQR, 21\%-25\%).

Table 2 details operative characteristics. CABG was performed in $695(78 \%)$ patients, aortic valve surgery in 289 
TABLE 2. Perioperative characteristics and postoperative outcomes

\begin{tabular}{|c|c|}
\hline Variable & Total $(\mathbf{N}=\mathbf{8 9 2})$ \\
\hline \multicolumn{2}{|l|}{ Surgical era } \\
\hline 1993-1999 & $320(35.9)$ \\
\hline $2000-2006$ & $324(36.3)$ \\
\hline 2007-2014 & $248(27.8)$ \\
\hline Coronary artery bypass graft surgery* & $695(77.9)$ \\
\hline Aortic valve surgery* & $289(32.3)$ \\
\hline Mitral valve surgery $*, \dagger$ & $133(14.9)$ \\
\hline \multicolumn{2}{|l|}{ Surgical procedure } \\
\hline $\begin{array}{l}\text { Isolated coronary artery bypass } \\
\text { graft }\end{array}$ & $496(55.6)$ \\
\hline Isolated valve & $197(22.1)$ \\
\hline $\begin{array}{l}\text { Coronary artery bypass } \\
\text { graft }+ \text { valve }\end{array}$ & $199(22.3)$ \\
\hline \multicolumn{2}{|l|}{ Surgical status } \\
\hline Elective & $580(65.0)$ \\
\hline Urgent & $270(30.3)$ \\
\hline Emergent & $42(4.7)$ \\
\hline \multicolumn{2}{|l|}{ Intra-aortic balloon pump use } \\
\hline Preoperative & $112(12.6)$ \\
\hline Intraoperative & $141(15.8)$ \\
\hline Postoperative & $10(1.1)$ \\
\hline Coronary artery bypass time (min) & $92(68-121)$ \\
\hline Crossclamp time (min) & $55(40-74)$ \\
\hline \multicolumn{2}{|l|}{ Number of bypass grafts $(n=695)$} \\
\hline 1 & $94(13.5)$ \\
\hline 2 & $116(16.7)$ \\
\hline 3 & $286(41.1)$ \\
\hline $4+$ & 199 (28.6) \\
\hline \multicolumn{2}{|l|}{ Internal thoracic artery use $\ddagger$} \\
\hline Left & $548(78.8)$ \\
\hline Right & $10(1.7)$ \\
\hline Bilateral & $16(2.3)$ \\
\hline $\begin{array}{l}\text { Complete anatomic coronary } \\
\text { revascularization } \ddagger\end{array}$ & $549(79.0)$ \\
\hline $\begin{array}{l}\text { Pacemaker/automatic implantable } \\
\text { cardioverter-defibrillator implant }\end{array}$ & $19(2.1)$ \\
\hline \multicolumn{2}{|l|}{$\begin{array}{l}\text { Extracorporeal membrane } \\
\text { oxygenation }\end{array}$} \\
\hline Intraoperative & $3(0.3)$ \\
\hline Postoperative & $3(0.3)$ \\
\hline Reoperation for bleeding & $49(5.5)$ \\
\hline Atrial fibrillation & $270(30.2)$ \\
\hline Stroke & $19(2.1)$ \\
\hline Prolonged ventilation $\S$ & $263(29.5)$ \\
\hline Renal failure & $71(8.0)$ \\
\hline Myocardial infarction & $3(0.4)$ \\
\hline Operative mortality & $67(7.5)$ \\
\hline
\end{tabular}

TABLE 2. Continued

\begin{tabular}{lc}
\hline \multicolumn{1}{c}{ Variable } & Total $(\mathbf{N}=\mathbf{8 9 2})$ \\
\hline Hospital length of stay (d) & $8(6-13)$ \\
Follow-up (y) & $5.0(1.6-8.7)$ \\
\hline
\end{tabular}

Values are presented as $\mathrm{n}(\%)$ or median (interquartile range). $*$ A total of 225 points $(25 \%)$ had multiple procedures at the time of surgery. †Eighty-five patients $(64 \%)$ underwent mitral valve repair and $48(36 \%)$ underwent mitral valve replacement. $\ddagger$ Percentages are from a denominator of 695 patients who underwent coronary artery bypass graft surgery. §Prolonged ventilation defined as $>24$ hours of mechanical ventilation.

$(32 \%)$ and mitral valve surgery in $133(15 \%)$. Multiple procedures were performed in $25 \%(\mathrm{n}=225)$. Considered alternatively, 496 patients $(56 \%)$ underwent isolated CABG, 197 (22\%) underwent isolated valve surgeries, and $199(22 \%)$ underwent CABG and valve surgery.

\section{Early Postoperative Outcomes}

Table 2 outlines early postoperative outcomes. Operative mortality was $7.5 \%(n=67)$, without significantly different mortality between isolated CABG $(6.7 \%)$, isolated valve surgery $(7.6 \%)$, or combined CABG and valve surgery $(9.6 \%)(P=.43)$. Over time, operative mortality decreased significantly $(1993-1999=10.3 \%$ vs $2000-2006=7.1 \%$ vs $2007-2014=4.4 \% ; P$ for trend $=.008$ ). This was most evident in patients without prior cardiac surgery $(9.9 \%$ vs $5.6 \%$ vs $1.9 \% ; P<.001)$ but not in those with prior surgery ( $14.6 \%$ vs $14.3 \%$ vs $18.4 \% ; P=.450)$.

Predictors of operative mortality are outlined in Table E1. The multivariable model with greatest discriminatory power included older age (odds ratio [OR], 1.09 per 5 years, 95\% CI, 0.95-1.24; $P=.196)$ NYHA functional class IV (OR, $1.88 ; 95 \% \mathrm{CI}, 1.05-3.44 ; P=.036$ ), prior cardiac surgery $(\mathrm{OR}, 2.13 ; 95 \% \mathrm{CI}, 1.15-3.85 ; P=.014)$, peripheral vascular disease (PVD) (OR, 2.55; 95\% CI, 1.46-4.44; $P<.001)$, emergency surgery (OR, 2.68; 95\% CI, 1.14$5.98 ; P=.019)$, and IABP use (OR, $4.95 ; 95 \% \mathrm{CI}, 2.81$ 8.94; $P<.001)(\mathrm{C}$-index $=0.81)$. Older age, although not independently predictive, was deemed of sufficient clinical importance by expert consensus to warrant inclusion in the final model.

To inform surgical planning in the elective, clinical setting, we focused on 2 nonacute, reliable, and reproducible predictors: prior cardiac surgery and NYHA functional class IV symptoms. Operative death occurred in $14.8 \%$ (21 out of 142 ) and $6.1 \%$ (46 out of 750) of patients with and without prior cardiac surgery, respectively $(P<.001)$. Operative mortality impacted $4.2 \%$ patients ( 20 out of 481 ) with NYHA functional class I through III symptoms versus $11.4 \%$ (47 out of 413) of those with functional class IV symptoms $(P<.001)$. Operative mortality risk imparted by presence of both variables was additive, with a 4-fold 


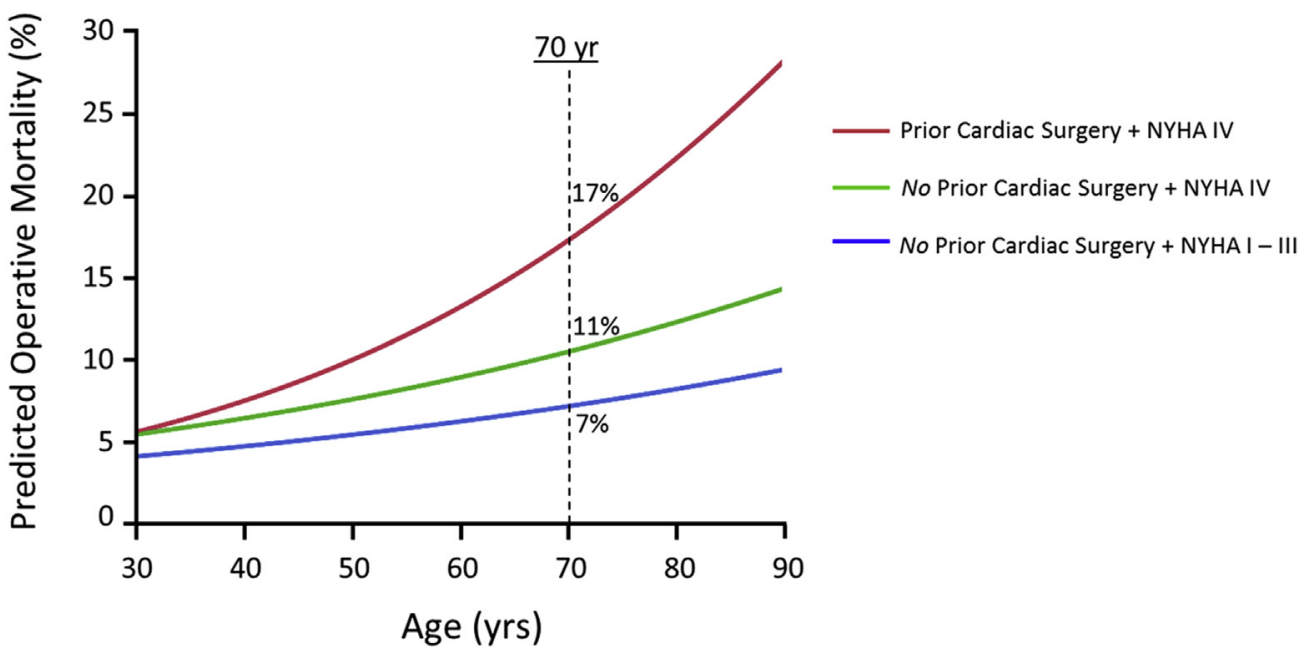

FIGURE 2. Predicted probability of early operative mortality by age, prior history of cardiac surgery, and New York Heart Association (NYHA) functional class IV symptoms.

increase in mortality risk versus those free of both variables (OR, 3.95; 95\% CI, 1.61-9.72; $P=.003$ ).

Plotting the relationship between age and predicted probability of operatively mortality, we again observed the deleterious influence associated with NYHA functional class IV symptoms and a history of prior cardiac surgery (Figure 2). Among patients with $\mathrm{EF} \leq 25 \%$, a 70 -year-old's probability of early death was $7 \%$ if he or she had NYHA functional class I through III symptoms and no prior cardiac surgery. Predicted risk was $11 \%$ in the presence of NYHA functional class IV symptoms, and increased to $17 \%$ in those with both NYHA functional class IV symptoms and prior surgery.

Six patients required postoperative temporary mechanical circulatory support (extracorporeal membrane oxygenation), with 5 patients experiencing early mortality.

\section{Long-Term Follow-up and Survival}

Median follow-up was 5.0 years (interquartile range, 1.68.7 years). Follow-up was complete (ie, death, follow-up beyond January 1, 2016, or 5-year follow-up) for 95\% of patients (844 out of 892). In total, 654 patients $(73 \%)$ died, with median time till death of 4.8 years (IQR, 1.58.4 years). Overall, 1-, 3-, and 5-year survival was $83 \%$, $71 \%$, and $59 \%$, respectively (Figure E1). Long-term survival was comparable across the 3 surgical eras $(1$ year $=81.1 \%$ vs $83.3 \%$ vs $85.0 \%, 3$ years $=69.6 \%$ vs $70.3 \%$ vs $75.7 \%$, and 5 years $=56.8 \%$ vs $58.5 \%$ vs $65.6 \% ; P=.610)$. Stratification by history of prior cardiac surgery demonstrated inferior late survival in patients with versus those without prior surgery $(P<.001)$ (Figure 3$)$. On covariate adjustment, prior cardiac surgery predicted a $60 \%$ increase in the hazard of late death (HR, $1.59 ; 95 \% \mathrm{CI}$, 1.26-4.15; $P<.001$ ) (Table 3).
To further stratify risk, we analyzed the subset of 750 patients without prior cardiac surgery. In multivariable analysis, older age (HR, 1.04; 95\% CI, 1.03-1.05; $P<.001$ ), male sex (HR, 1.35; 95\% CI, 1.08-1.68; $P=.008)$, PVD (HR, 1.52; 95\% CI, 1.25-1.84; $P<.001$ ), IABP use (HR, $1.36 ; 95 \% \mathrm{CI}, 1.12-1.67 ; P=.003)$, and NYHA functional class IV symptoms (HR, 1.22; 95\% CI, 1.03-1.46; $P=.024)$ remained predictive of inferior late survival. An age threshold $\geq 70$ years defined patients at greatest late mortality risk. Among patients with $\mathrm{EF} \leq 25 \%$, and in the absence of prior surgery, survival was lower in those aged $\geq 70$ years versus $<70$ years $(P<.001)$ (Figure 4$)$. By multivariable analysis, age $\geq 70$ years almost doubled late mortality risk (HR, $1.86 ; 95 \% \mathrm{CI}, 1.56-2.26 ; P<.001)$. In

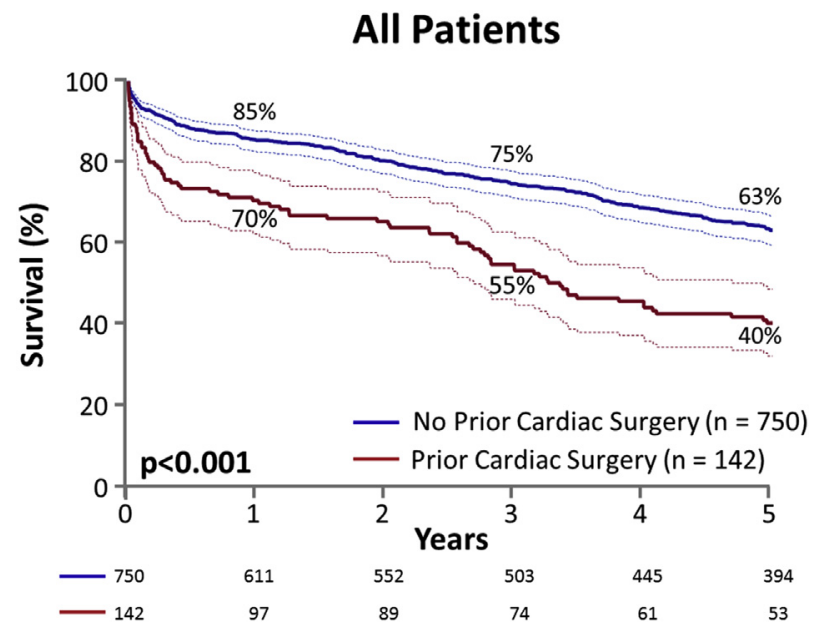

FIGURE 3. Long-term unadjusted survival estimates following conventional cardiac surgery in patients with ejection fraction $\leq 25 \%$ by Prior cardiac surgery $(\mathrm{n}=892)$. Dotted lines represent $95 \%$ confidence intervals. 
TABLE 3. Multivariable predictors of late all-cause mortality in patients with ejection fraction $\leq \mathbf{2 5} \%$

\begin{tabular}{lcc}
\hline & \multicolumn{2}{c}{ All patients $(\mathbf{N}=\mathbf{8 9 2})$} \\
\cline { 2 - 3 } \multicolumn{1}{c}{ Variable } & $\begin{array}{c}\text { Hazard ratio }(95 \% \\
\text { Confidence interval) }\end{array}$ & $\boldsymbol{P}$ value \\
\hline Older age* & $1.16(1.10-1.22)$ & $<.001$ \\
Male sex & $1.22(1.01-1.50)$ & .043 \\
\hline $\begin{array}{l}\text { New York Heart Association } \\
\quad \text { functional class IV } \dagger\end{array}$ & $1.25(1.07-1.46)$ & .006 \\
$\begin{array}{l}\text { Intra-aortic balloon pump } \\
\quad \text { use } \neq\end{array}$ & $1.39(1.16-1.65)$ & $<.001$ \\
\hline $\begin{array}{l}\text { Peripheral vascular disease } \\
\text { Prior cardiac surgery }\end{array}$ & $1.55(1.30-1.83)$ & $<.001$ \\
\hline
\end{tabular}

*Age increase by 5 -year increments. †Compared with New York Heart Association functional classes I through III. ‡Pre- or intraoperative intra-aortic balloon pump use.

patients without prior surgery and age $\geq 70$ years, late mortality was further augmented by concomitant NYHA functional class IV symptoms (HR, 2.25; 95\% CI, 1.8-7.12; $P<.001$ ) (Table E2) (Figure 5).

Forced as a covariate into multivariable models, surgical era did not predict late mortality (1993-1999 vs 2007-2014: HR, 0.96; $P=.716$ and 2000-2006 vs 2007-2014: HR 1.06; $P=.638)$. When surgical procedure types were forced as covariates, CABG (HR, 0.83; $P=.080$ ), aortic valve surgery $(\mathrm{HR}, 1.08 ; P=.383$ ), and mitral valve surgery (HR, $0.98 ; P=.849)$ did not significantly influence late death. In each of these models, older age, male sex, PVD, IABP use, NYHA functional class IV symptoms, and a history of prior surgery remained predictive of inferior long-term survival (Table E3).

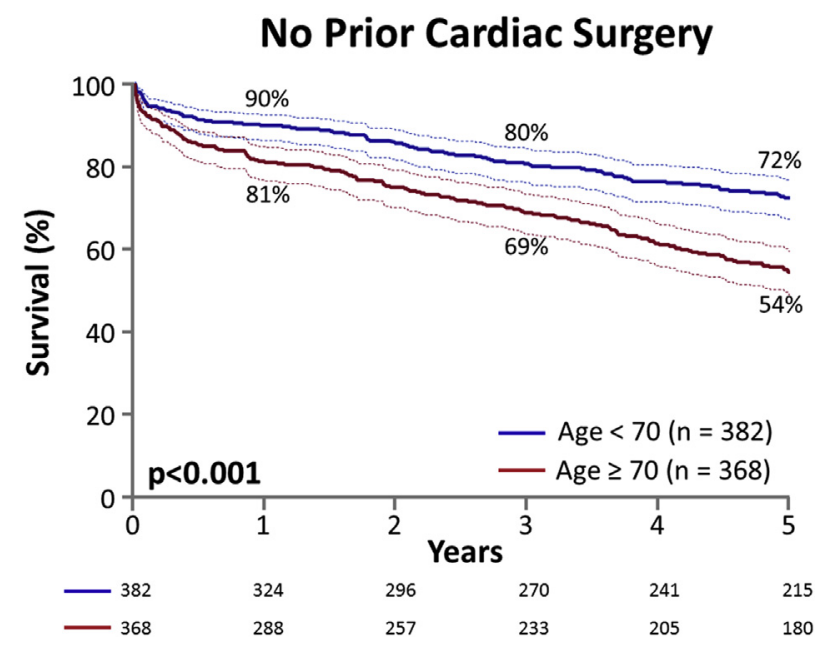

FIGURE 4. Long-term unadjusted survival estimates following conventional cardiac surgery in patients with ejection fraction $\leq 25 \%$ and no prior cardiac surgery by age $\geq 70$ years $(\mathrm{n}=750)$. Dotted lines represent $95 \%$ confidence intervals.

\section{DISCUSSION}

\section{Study Rationale and Key Findings}

Having demonstrated promise in the heart failure milieu, ${ }^{17,18}$ durable MCS has been suggested as a potentially viable alternative in managing severe $\mathrm{LV}$ dysfunction and coexistent coronary or valve disease. ${ }^{19}$ However, there remains sparse data comparing outcomes of these disparate therapeutic approaches in complex patients. This is partly due to ambiguity regarding which patients with severe LV dysfunction are at highest risk following conventional surgery, and thus may benefit most from durable MCS. Analyzing 892 patients with $\mathrm{EF} \leq 25 \%$ undergoing coronary and/or valve surgery, our study demonstrates that although conventional surgery may be performed safely in many, early mortality is doubled in those with a history of prior surgery or NYHA functional class IV symptoms, and quadrupled in the presence of both. We detail that the detrimental effects of prior surgery and functional class IV symptoms on survival persist during long-term follow-up, and are compounded by advanced age (ie, $\geq 70$ years). Although offering a more granular understanding of the magnitude of mortality risk incurred by those with severely depressed EF, our definition of highrisk subsets may serve to inform patient selection for future studies assessing MCS as an alternate or adjunctive strategy to conventional surgery in this challenging population.

\section{Early Determinants of Operative Mortality}

Our operative mortality rate of $7.5 \%$ aligns with studies of patients with LV dysfunction, reporting estimates between $4 \%$ and $20 \% .^{2,3,5,13,26-29}$ In the large current study

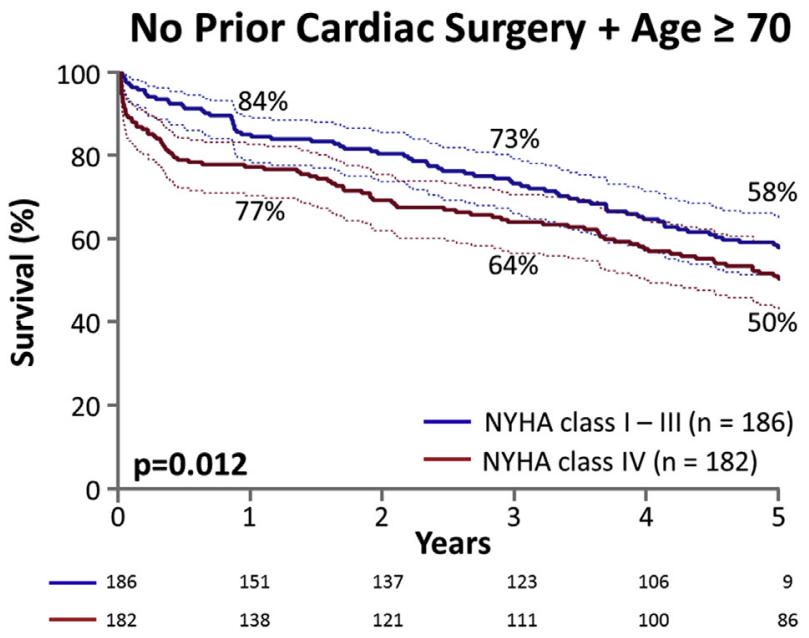

FIGURE 5. Long-term unadjusted survival estimates following conventional cardiac surgery in patients with ejection fraction $\leq 25 \%$, no prior cardiac surgery and age $\geq 70$ years by New York Heart Association (NYHA) functional class $(\mathrm{n}=368)$. Dotted lines represent $95 \%$ confidence intervals. 
addressing patients with advanced ventricular impairment $(\mathrm{EF} \leq 25 \%)$ we demonstrate that emergent surgery, PVD, IABP use, NYHA functional class IV symptoms, and prior cardiac surgery independently predict early operative demise. Deprived of an opportunity for patient optimization, emergency surgery unsurprisingly compromises operative outcomes. The prognostic value of PVD may relate to its being a marker of a notable underlying burden of atherosclerotic disease. Although IABP placement intends to augment cardiac function, its need signifies impending or fulminant pump failure. ${ }^{30}$ Therefore, IABP use is another, albeit late, marker of critical ventricular impairment. NYHA functional class IV status is similarly a valuable proxy of late-stage LV dysfunction, and consequently is indicative of increased operative death risk. ${ }^{31}$ Finally, in patients with prior cardiac surgery, technical challenges such as mediastinal adhesions and potential injury to bypass grafts may augment operative mortality. ${ }^{32}$ Indeed, several of our identified predictors of operative mortality have been shown to be of detriment to patients with LV dysfunction. ${ }^{2,3,13,26,29}$ Nevertheless, we demonstrate to our knowledge for the first time that in patients with $\mathrm{EF} \leq 25 \%$, early mortality risk conferred by prior surgery, and NYHA functional class IV symptoms is additive, and 4-fold greater in their joint presence.

The demonstrated decline in operative mortality rates over time is encouraging, attesting that in contemporary practice conventional cardiac surgery may be safely offered with acceptable risk to many patients with $\mathrm{EF} \leq 25 \%$. Although this observation may be attributed to improvements in operative technique and/or methods for patient selection, this temporal trend did not endure in patients with prior cardiac surgery. In this subset, operative mortality was persistently elevated across all eras, further supporting its designation as a significant marker of mortality risk in patients with $\mathrm{EF} \leq 25 \%$.

\section{Markers of Long-Term Mortality Risk}

It is abundantly clear that prior cardiac surgery portends inferior survival beyond the early postoperative phase. Specifically, it independently increased late mortality risk by $60 \%$. Considered alternatively, risk of late death in patients with $\mathrm{EF} \leq 25 \%$ undergoing their first cardiac surgery was less than two-thirds the risk incurred by those having their second operation. The effects of prior surgery on longterm prognosis likely extend beyond technical challenges, and may be partly credited to reintervention being a surrogate for chronicity of underlying cardiac disease. In patients with severe LV dysfunction, failure of medical therapy and need for reoperation may represent a final common pathway for adverse ventricular remodeling.

Although not an independent determinant of early mortality, older age was significantly predictive of late death $(P<.001)$. In patients with $\mathrm{EF} \leq 25 \%$ and without prior surgery, an age threshold of 70 years almost doubled the risk of late death. Although prior reports attest to the detrimental effects of older age in those with LV dysfunction, ${ }^{3,13}$ we uniquely demonstrate that coexistent age $\geq 70$ years and NYHA functional class IV symptoms defines a subset at magnified risk of late mortality. The survival disadvantage imparted by NYHA functional class IV symptoms appeared largely concentrated in the first year after surgery. It may hence be proposed that NYHA functional class symptoms indicate a patient's capacity to withstand the insult of major cardiac surgery, with NYHA functional class IV symptoms signifying great difficulty may be encountered in mounting a recovery during the first postoperative year. Finally, and in conflict with prior reports, ${ }^{29}$ our analyses failed to identify a significant relationship between surgery type and late survival. This perhaps suggests that in patients with $\mathrm{EF} \leq 25 \%$, ventricle function has degenerated sufficiently to negate any influence the index procedure may have on late survival. Alternatively, the predictive scope of other covariates such as prior surgery, NYHA functional class, and age may outweigh the effects of surgery type in patients with severe LV dysfunction.

\section{Implications in the MCS Era}

We present a novel tool for stratifying mortality risk in patients with $\mathrm{EF} \leq 25 \%$ referred for conventional coronary or valve surgery (Figure 6). Although DeRose and colleagues $^{13}$ previously proposed a risk allocation scheme for patients with LV dysfunction, we offer a simpler, stepwise, rules-based tool that is easily applied at the bedside without need for complex calculations. Our algorithm submits that in the context of $\mathrm{EF} \leq 25 \%$, patients with prior cardiac surgery, and those without prior surgery, but who present at age $\geq 70$ years, with concomitant functional class IV symptoms, constitute subsets at greatest mortality risk following conventional surgery. Although not intended to replace clinical judgment and expertise, this tool serves as a decision aid to guide risk counseling, alongside surgical and perioperative planning.

Although the model put forth by DeRose and colleagues ${ }^{13}$ proposes transplantation as a substitute to conventional surgery, the extrapolation herein is that high-risk subsets may benefit by considering durable MCS as an alternative or adjunctive approach. This sentiment was expressed by Maltais and colleagues. ${ }^{19}$ Assessing patients with concurrent coronary and mitral valve disease, they reported that despite a more severe comorbid profile in LVAD recipients, 30-day and 1-year survival was comparable to patients undergoing conventional surgery. ${ }^{19}$ The Interagency Registry for Mechanically Assisted Circulatory Support (INTERMACS) reports 1- and 3-year survival of $80 \%$ and $60 \%$, respectively, following implant of continuous-flow LVADs. ${ }^{18}$ Initially, these estimates appear at least comparable to survival in patients who underwent 


\section{Defining Mortality Risk in Patients with EF $\mathbf{2 5 \%}$ Referred to Conventional Cardiac Surgery}

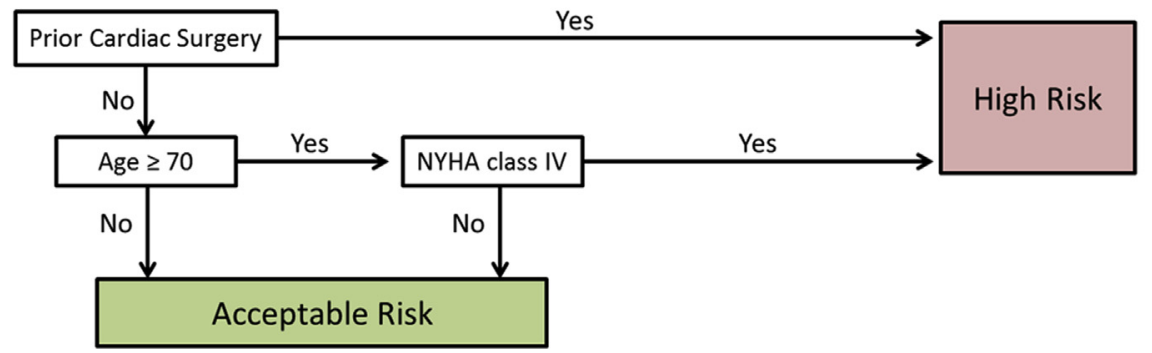

FIGURE 6. Defining mortality risk in patients with ejection fraction $\leq 25 \%$ referred for conventional cardiac surgery. NYHA, New York Heart Association.

conventional surgery and per our algorithm meet criteria for high-mortality risk (Figures 3 and 5). However, the quoted risk associated with MCS may be diluted by a more favorable risk profile (eg, younger or fewer prior surgeries) in the INTERMACS cohort versus the high-risk subsets in our study. By extension, such a raw and uncontrolled comparison may unfoundedly imply appropriateness or superiority of durable MCS over conventional surgery in this context. Without comprehensive data regarding inotropedependence and INTERMACS classification in our population, comparisons to INTERMACS data must be made cautiously. Although published outcomes of patients receiving durable MCS have been promising, the decision to use these technologies must not be trivialized. Boasting the potential for significant hemorrhagic, thrombotic, and infectious complications, this platform subjects patients to substantial risk. ${ }^{20-22}$ We therefore emphasize that if durable MCS is to be considered as an adjunct/substitute, this must be done cautiously and only in those at greatest risk with conventional surgery, who would potentially benefit the most.

The notion that durable MCS may offer survival benefit in our high-risk subsets is purely speculative. Appropriateness of MCS in this setting can only be established by directly evaluating outcomes following durable MCS versus conventional surgery in well-matched populations. Preoperative risk assessment in patients undergoing conventional surgery is more extensively characterized than among those undergoing durable MCS, further supporting the need for restraint when extrapolating our findings. Review of what limited data exist reveals that several variables that hinder survival in patients with LV dysfunction undergoing conventional surgery are similarly prognostically disadvantageous in the context of durable MCS. ${ }^{18}$ Ultimately, the current study characterizes distinct patient subsets with severe LV dysfunction that are at enduringly elevated mortality risk if undergoing conventional surgery. By informing patient candidacy and cohort selection, it forges a solid foundation for future comparative effectiveness studies that are needed to understand whether durable
MCS has a legitimate role to play in patients referred for conventional cardiac surgery with severe LV dysfunction.

\section{LIMITATIONS}

Conclusions derived from the present study are necessarily limited by the retrospective design, and potential for selection bias. We cannot comment on the possibility that some patients with $\mathrm{EF} \leq 25 \%$ may have undergone alternative therapies-including transcatheter approaches or durable MCS - and were thus not eligible for inclusion in the present investigation. These exclusion criteria also limit the generalizability of our findings. Potential viability of transcatheter valve interventions in subsets of high-risk patients with severe LV dysfunction, although not definitively established, remains intriguing. It may be proposed that the transcatheter platform should enter the debate alongside durable MCS for consideration as a therapeutic alternative to conventional surgery in this challenging population. Of critical importance is incorporation of a heart team approach in the management of these patients. This ensures comprehensive preoperative evaluation of cardiac reserve beyond echocardiographic measurement of $\mathrm{EF}$, and that appropriate consideration has been given to established interventional options such as biventricular pacing and percutaneous revascularization. Finally, it warrants recognition that algorithms and age thresholds laid forth herein are specific to our derivation cohort, mandating external validation.

\section{CONCLUSIONS}

In patients referred for conventional cardiac surgery who have $\mathrm{EF} \leq 25 \%$, prior cardiac surgery, and NYHA functional class IV symptoms-especially in the context of age $\geq 70$ years—are independently detrimental to patient survival in both early and late postoperative follow-up. This highlights the importance of judicious patient selection and preoperative cardiac optimization in this challenging population to maximize patient survival. Such high-risk subsets must represent the focus of future studies aiming 
to establish whether a prognostic benefit may be gained by incorporating a strategy of durable MCS.

\section{Webcast}

You can watch a Webcast of this AATS meeting presentation by going to: https://aats.blob.core.windows.net/ media/17AM/2017-05-02/RM306/05-02-17_Room306_ 1641_Thalji.mp4.

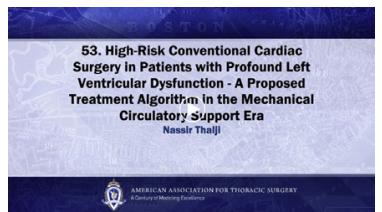

\section{Conflict of Interest Statement}

Dr Maltais receives research funding from the National Institutes of Health and Clearflow, Inc, and serves on the advisory board of Abbott and Medtronic. All other authors have nothing to disclose with regard to commercial support.

\section{References}

1. Society of Thoracic Surgeons Adult Cardiac Surgery Database executive summary. Available at: http://www.sts.org/sts-national-database/database-managers/ executive-summaries. Accessed January 8, 2017.

2. Filsoufi F, Rahmanian PB, Castillo JG, Chikwe J, Kini AS, Adams DH. Results and predictors of early and late outcome of coronary artery bypass grafting in patients with severely depressed left ventricular function. Ann Thorac Surg. 2007; 84:808-16

3. Topkara VK, Cheema FH, Kesavaramanujam S, Mercando ML, Cheema AF, Namerow PB, et al. Coronary artery bypass grafting in patients with low ejection fraction. Circulation. 2005;112(Suppl):344-50.

4. Antunes PE, de Oliveira JMF, Antunes MJ. Coronary surgery with noncardioplegic methods in patients with advanced left ventricular dysfunction: immediate and long term results. Heart. 2003;89:427-31.

5. Bouchart F, Tabley A, Litzler PY, Haas-Hubscher C, Bessou JP, Soyer R Myocardial revascularization in patients with severe ischemic left ventricular dysfunction. Long term follow-up in 141 patients. Eur J Cardiothorac Surg. 2001;20:1157-62.

6. Trachiotis GD, Weintraub WS, Johnston TS, Jones EL, Guyton R, Craver JM. Coronary artery bypass grafting in patients with advanced left ventricular dysfunction. Ann Thorac Surg. 1998;66:1632-9.

7. Nishimura RA, Otto CM, Bonow RO, Carabello BA, Erwin JP, Guyton RA, et al. 2014 AHA/ACC guideline for the management of patients with valvular heart disease. J Am Coll Cardiol. 2014;1-234.

8. Eagle K, Guyton R, Davidoff R, Edwards FH, Ewy G, Gardner TJ, et al. ACC/ AHA 2004 guideline update for coronary artery bypass graft surgery: a report of the American College of Cardiology/American Heart Association task force on practice guidelines. Circulation. 2004;110:1168-76.

9. Pai RG, Varadarajan P, Razzouk A. Survival benefit of aortic valve replacement in patients with severe aortic stenosis with low ejection fraction and low gradient with normal ejection fraction. Ann Thorac Surg. 2008;86:1781-9.

10. Pereira JJ, Lauer MS, Bashir M, Afridi I, Blackstone EH, Stewart WJ, et al. Survival after aortic valve replacement forsevere aortic stenosis with low transvalvular gradients and severe left ventricular dysfunction. J Am Coll Cardiol. 2002; 39:1356-63.

11. Chaliki HP, Mohty D, Avierinos JF, Scott CG, Schaff HV, Tajik AJ, et al. Outcomes after aortic valve replacement in patients with severe aortic regurgitation and markedly reduced left ventricular function. Circulation. 2002; 106:2687-93.
12. Rothenburger M, Drebber K, Tjan TD, Schmidt C, Schmid C, Wichter T, et al Aortic valve replacement for aortic regurgitation and stenosis, in patients with severe left ventricular dysfunction. Eur J Cardiothorac Surg. 2003;23:703-9.

13. DeRose JJ, Toumpoulis IK, Balaram SK, Ioannidis JP, Belsley S, Ashton RC, et al. Preoperative prediction of long-term survival after coronary artery bypass grafting in patients with low left ventricular ejection fraction. J Thorac Cardiovasc Surg. 2005;129:314-21.

14. Lorusso R, La Canna G, Ceconi C, Borghetti V, Totaro P, Parrinello G, et al. Long-term results of coronary artery bypass grafting procedure in the presence of left ventricular dysfunction and hibernating myocardium. Eur J Cardiothorac Surg. 2001;20:937-48.

15. Carr JA, Haithcock BE, Paone G, Bernabei AF, Silverman NA. Survival after isolated coronary artery bypass grafting in patients with severe left ventricular dysfunction. Ann Thorac Surg. 2009;87:1106-12.

16. Velazquez E, Lee K, Jones R, Al-Khalidi H, Hill J, Panza J, et al. Coronary artery bypass surgery in patients with ischemic cardiomyopathy. $N$ Engl J Med. 2016; 374:1511-20.

17. Uriel N, Adatya S, Mehra MR. Evolution in mechanical circulatory support: are we at the precipice of a disruptive innovation? J Am Coll Cardiol. 2015;66:2590-3.

18. Kirklin JK, Naftel DC, Pagani FD, Kormos RL, Stevenson LW, Blume ED, et al. Seventh INTERMACS annual report: 15,000 patients and counting. J Heart Lung Transpl. 2015;34:1495-504.

19. Maltais S, Tchantchaleishvili V, Schaff HV, Daly RC, Suri RM, Dearani JA, et al. Management of severe ischemic cardiomyopathy: left ventricular assist device as destination therapy versus conventional bypass and mitral valve surgery. $J$ Thorac Cardiovasc Surg. 2014; 147:1246-50.

20. DeVore AD, Stewart GC. The risk of stroke on left ventricular assist device support. JACC Heart Fail. 2017;5:712-4.

21. Suarez J, Patel CB, Felker GM, Becker R, Hernandez AF, Rogers JG. Mechanisms of bleeding and approach to patients with axial-flow left ventricular assist devices. Circ Heart Fail. 2011;4:779-84.

22. Toba FA, Akashi H, Arrecubieta C, Lowy FD. Role of biofilm in Staphylococcus aureus and Staphylococcus epidermidis ventricular assist device driveline infections. J Thorac Cardiovasc Surg. 2011;141:1259-64.

23. Lund LH, Matthews J, Aaronson K. Patient selection for left ventricular assist devices. Eur Heart J. 2010;12:434-43.

24. Yancy CW, Jessup M, Bozkurt B, Butler J, Casey DE, Drazner MH, et al. 2013 $\mathrm{ACCF} / \mathrm{AHA}$ guideline for the management of heart failure: executive summary J Am Coll Cardiol. 2013:62:1495-539.

25. Society of Thoracic Surgeons Adult Cardiac Surgery Data specifications. Available at: http://www.sts.org/sts-national-database/database-managers/adultcardiac-surgery-database/data-collection. Accessed January 9, 2017.

26. Nardi P, Pellegrino A, Scafuri A, Colella D, Bassano C, Polisca P, et al. Longterm outcome of coronary artery bypass grafting in patients with left ventricular dysfunction. Ann Thorac Surg. 2009;87:1401-8.

27. Hillis GS, Zehr KJ, Williams AW, Schaff HV, Orzulak TA, Daly RC, et al Outcome of patients with low ejection fraction undergoing coronary artery bypass grafting: renal function and mortality after 3.8 years. Circulation. 2006; 114(Suppl):I414-9.

28. Connolly HM, Oh JK, Schaff HV, Roger VL, Osborn SL, Hodge DO, et al. Severe aortic stenosis with low transvalvular gradient and severe left ventricular dysfunction: result of aortic valve replacement in 52 patients. Circulation. 2000;101:1940-6.

29. Pieri M, Belletti A, Monaco F, Pisano A, Musu M, Dalessandro V, et al. Outcome of cardiac surgery in patients with low preoperative ejection fraction. BMC Anesthesiol. 2016:16:1-10.

30. Parissis H, Leotsinidis M, Akbar MT, Apostolakis E, Dougenis D. The need for intra aortic balloon pump support following open heart surgery: risk analysis and outcome. J Cardiothorac Surg. 2010;5:20.

31. Argenziano M, Spotnitz HM, Whang W, Bigger JT, Parides M, Rose EA. Risk stratification for coronary bypass surgery in patients with left ventricular dysfunction - analysis of the coronary artery bypass grafting patch trial database. Circulation. 1999;100(Suppl):119-24.

32. Park CB, Suri RM, Burkhart HM, Greason KL, Dearani JA, Schaff HV, et al. Identifying patients at particular risk of injury during repeat sternotomy: analysis of 2555 cardiac reoperations. J Thorac Cardiovasc Surg. 2010;140:1028-33.

Key Words: heart failure, ventricular dysfunction, coronary artery bypass, valve surgery 


\section{Discussion}

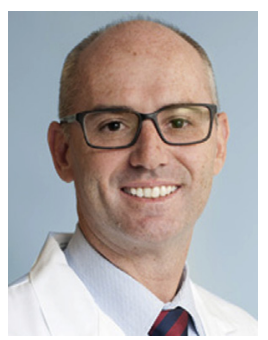

Dr David D'Alessandro (Boston,

Mass). I want to thank the Association and our moderators for the opportunity to discuss this article and the authors for providing the manuscript to review in advance. Dr Thalji, I commend you and your coauthors for this thoughtful review of the Mayo Clinic's 20-year experience operating on patients with severely low ejection fractions (EFs) when performing routine cardiac surgery. The long-term results of your entire cohort are commendable, a 5-year survival of $60 \%$, which is higher than most published series of low EF surgery patients, yet we don't know anything about their functional status or quality of life, and, as you point out, those with a history of prior cardiac surgery, those that are older or with more advanced disease had less good results. You and your colleagues make a very reasonable suggestion that perhaps in the riskiest of these patients, mechanical circulatory support should at least be considered.

I have a concern and a few questions. The concern is that prior cardiac surgery, advanced age, and more advanced heart failure are all also risk factors for left ventricular assist device implantation. I suggest that we perhaps need to look more closely at our results with left ventricular assist device surgery in this cohort of patients.

In regard to my question, what we all really want to know is when is it appropriate to give up on a chance for ventricular recovery? In your review, did you gain any insight into perhaps things that are associated with ventricle recovery? Did you look at EFs before and after surgery and gain any insight in that regard?

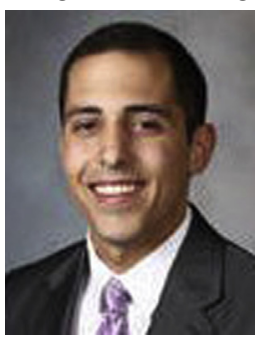

Dr Nassir M. Thalji (Rochester, Minn). Thank you, Dr D'Alessandro, for an excellent question. We don't currently have follow-up EF data but we are currently collecting it for a following study. With that in mind, I think we can glean some insight from the results that we have here with regard to patient survival. Specifically, we looked at the patients who had improved survival, namely those without a history of prior surgery coming to their first operation, and those who were perhaps better preoperatively optimized in light of younger age and absence of functional class IV symptoms. Now, we understand that survival does not equate to left ventricle recovery; however, it allows for a reasonable surrogate in this situation. But we do look forward to having that EF follow-up data as well as followup classification data.

Dr D'Alessandro. The second question is, what were the reasons for reoperation? Is this a group of patients that perhaps should be considered for percutaneous approaches, transcatheter aortic valve replacement, MitraClip (Abbott, Abbott Park, Ill), perhaps ventricular-supported high-risk coronary interventions? Do we need to be doing reoperative surgery on these patients at all?

Dr Thalji. That is a very intriguing question. The debate that we are looking at here, mechanical circulatory support versus conventional surgery, is certainly not mutually exclusive from the debate of surgical aortic valve replacement versus transcatheter aortic valve replacement and so on.

To answer your question, of 142 patients who underwent reoperation, approximately $30 \%$ were coming for coronary artery bypass grafting surgery, $20 \%$ were coming for isolated valve surgery, and the remaining $50 \%$ were coming for combined coronary and valve surgery.

So an argument can be made that perhaps a transcatheter approach should be considered as another alternative to conventional surgery in these patients, but it is certainly not an easy decision. A lot of factors have to be taken into account, namely, competing risks of death, and what is your patient's expected long-term survival. Now, transcatheter platforms may allow you to offer a patient a potentially improved short-term survival outcome compared with conventional surgery. Patients who had a history of prior cardiac surgery had detrimental long-term outcomes, and as it stands, we don't have a clear picture or understanding of what the long-term outcomes of transcatheter valve surgery are. But we do have a pretty good idea of what the outcomes are with left ventricular assist device surgery, and it's pretty darn good.

So, in summary, whereas transcatheter surgery may allow tempering of the outcomes in the short term, it may not necessarily obviate the need for mechanical circulatory support in the long term. But it is certainly an intriguing question and worth studying.

Dr D'Alessandro. A final question. Is it time for a randomized clinical trial to answer this question?

Dr Thalji. In brief, if it's not time, we are very close. We are currently undertaking another study whereby we are looking at these high-risk subsets that we have identified, matching those who had conventional surgery versus mechanical circulatory support, to hopefully corroborate these high-risk subsets and perhaps refine the definition. I look forward to seeing that trial.

Dr D'Alessandro. It would be a hard trial to do and a hard trial to power. Nicely presented. Thank you.

Dr Thalji. I agree. Thank you very much. I think that certainly is among the main challenges to such a trial: Sufficient equipoise to randomize enough people to each arm. 


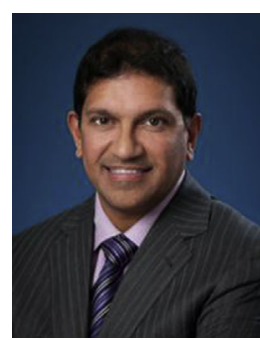

Dr Vivek Rao (Toronto, Ontario, Canada). Did you look at pulmonary hypertension as a covariate here? Certainly in my practice that's something that raises a red flag to me: A patient with high pulmonary artery pressures as he or she approaches an operation. Can you comment on that?

Dr Thalji. We didn't actually have data on pulmonary hypertension or maximum oxygen use in this setting.

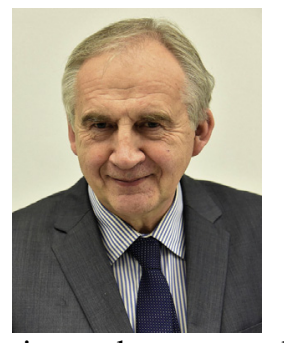

Dr Marian Zembala (Zabrze, Poland). In 2017, we taught our students and our residents that EF is certainly not enough. It's very, very little. In your presentation I am missing the concept, because if you are speaking about low EF ischemia patients, it is different from when a patient does not have ischemia. The first can be straightforward for cardiac surgery, especially in a patient with angina and viable muscle. If a patient does not have ischemia, but only heart failure, then they have a higher predicted mortality, and they may have other comorbidities such as kidney failure, chronic obstructive pulmonary disease, advanced age, and others. I did not see this in the presentation.

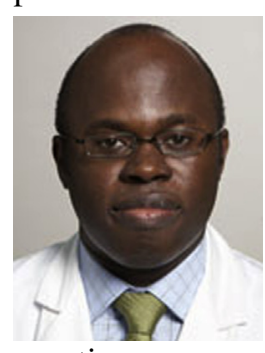

question.

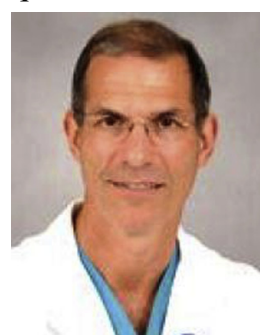

Dr Anelechi C. Anyanwu (New York, $N Y$ ). We will take the last question. You do not need to respond to this because he made a statement. You have no response, I am sure, because basically your article has mixed in too many apples, oranges, and different fruits together. So we will take another

Dr Glenn Whitman (Baltimore, $M d$ ). When we discuss high-risk patients, frequently we do not dichotomize them the way this study suggests. We do not say: Choose mechanical circulatory support or conventional therapy. We frequently say: Let's have mechanical circulatory support as a backup. And you don't discuss that. So, for example, if you were to look at patients who had intra-aortic balloon pumps or, they had trouble coming off bypass to some degree and you immediately switched over and went to mechanical circulatory support, does that change the entire algorithm? I am interested in what you have to say about that.

Dr Thalji. I appreciate that. It is a very important question. We have a similar approach. If we have patients scheduled for conventional surgery who are at higher risk, for example, $\mathrm{EF}<20 \%$ and other comorbidities, we have them sit down with the ventricular assist device team or ventricular assist device specialist nurses to discuss the fact that they may ultimately require mechanical circulatory support, and have that modality as a backup. Those patients are not included in this study.

Going back to your comment about dichotomy, I agree that it is not as clear and simple as this. I think the current study was born from the notion that with our definitions of why certain patients should be considered for mechanical circulatory support, including maximum oxygen use and $\mathrm{EF} \leq 25 \%$, there is a big question mark about which way to go. What we are trying to demonstrate if you go to conventional surgery is that a lot of patients do well, but there is a subset of patients who do poorly, and may conceivably benefit from a ventricular assist device. But I take your point and agree that it's not clear-cut. Ultimately, our current study does not determine the appropriateness of ventricular assist device placement, but rather is aimed at identifying subsets at high risk with conventional surgery; thereby, informing patient selection in future studies that are needed to establish a potential role for ventricular assist device therapy.

Dr Anyanwu. We have to go on, but can you just answer yes or no: If you have a patient in your hospital with previous surgery with New York Heart Association functional class IV symptoms, aged 74 years, have your surgeons changed their practice, yes or no, in terms of whether they will do conventional left ventricular assist device placement at Mayo Clinic? Would Dr Schaff turn that patient down or not based on your study?

Dr Thalji. I don't want to speak for Dr Schaff. I would like to think in the future, yes.

Dr Anyanwu. So not just yet?

Dr Thalji. Correct. 


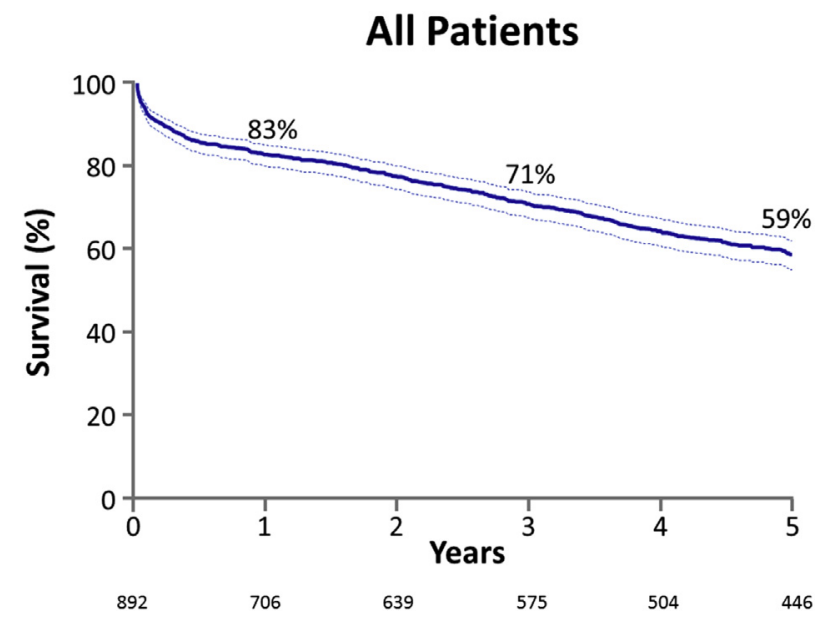

FIGURE E1. Long-term survival estimates following conventional cardiac surgery in patients with ejection fraction $\leq 25 \%(\mathrm{n}=892)$. Dotted lines represent $95 \%$ confidence intervals.

TABLE E1. Predictors of early operative mortality in patients with ejection fraction $\leq \mathbf{2 5} \%$

\begin{tabular}{|c|c|c|c|c|}
\hline \multirow[b]{2}{*}{ Variable } & \multicolumn{2}{|c|}{ Univariate analysis } & \multicolumn{2}{|c|}{ Multivariate model* } \\
\hline & OR $(95 \%$ CI $)$ & $P$ value & OR $(95 \%$ CI $)$ & $P$ value \\
\hline Older age $\dagger$ & $1.11(0.98-1.25)$ & .097 & $1.09(0.95-1.24)$ & .196 \\
\hline Male sex & $1.02(0.54-1.92)$ & .977 & - & - \\
\hline NYHA IV & $2.94(1.71-5.06)$ & $<.001$ & $1.88(1.05-3.44)$ & .036 \\
\hline Cerebrovascular accident & $2.06(0.96-4.39)$ & .062 & - & - \\
\hline Diabetes mellitus & $1.20(0.72-1.99)$ & .483 & - & - \\
\hline Hypercholesterolemia & $0.91(0.53-1.57)$ & .730 & - & - \\
\hline Family history CAD & $0.88(0.51-1.51)$ & .639 & - & - \\
\hline Hypertension & $0.99(0.58-1.71)$ & .982 & - & - \\
\hline Prior MI & $1.85(1.08-3.15)$ & .024 & - & - \\
\hline Obese, $\mathrm{BMI} \geq 30$ & $1.26(0.72-2.20)$ & .419 & - & - \\
\hline Peripheral vascular disease & $2.23(1.33-3.73)$ & .002 & $2.55(1.46-4.44)$ & $<.001$ \\
\hline Smoker & $0.88(0.52-1.51)$ & .653 & - & - \\
\hline Prior cardiac surgery & $2.66(1.53-4.61)$ & $<.001$ & $2.13(1.15-3.85)$ & .014 \\
\hline LMA disease & $1.23(0.71-2.11)$ & .461 & - & - \\
\hline 1993-1999 & $2.48(1.23-5.01)$ & .012 & - & - \\
\hline $2000-2006 \ddagger$ & $1.64(0.79-3.45)$ & .176 & - & - \\
\hline Emergent surgery & $5.03(2.40-10.54)$ & $<.001$ & $2.68(1.14-5.98)$ & .019 \\
\hline IABP use $\S$ & $6.54(3.81-11.22)$ & $<.001$ & $4.95(2.81-8.94)$ & $<.001$ \\
\hline CABG & $1.02(0.56-1.85)$ & .951 & - & - \\
\hline Aortic valve surgery & $1.05(0.62-1.80)$ & .848 & - & - \\
\hline Mitral valve surgery & $0.71(0.37-1.34)$ & .285 & - & - \\
\hline CPB time & $1.11(1.03-1.19)$ & .010 & - & - \\
\hline Crossclamp time & $1.13(0.25-5.16)$ & .875 & - & - \\
\hline
\end{tabular}

OR, Odds ratio; $C I$, confidence interval; $N Y H A$, New York Heart Association; $C A D$, coronary artery disease; $M I$, myocardial infarction; $B M I$, body mass index; $L M A$, left main artery; IABP, intra-aortic balloon pump; $C A B G$, coronary artery bypass grafting; $C P B$, cardiopulmonary bypass. *Overall model C-index $=0.81$. $\dagger$ Age increase by 5 -year increments. $\ddagger$ Compared with 2007-2014. §Pre- or intraoperative IABP use. 
TABLE E2. Multivariable predictors of late all-cause mortality in patients with ejection fraction $\leq 25 \%$ and without prior cardiac surgery

\begin{tabular}{|c|c|c|}
\hline \multirow[b]{2}{*}{ Variable } & \multicolumn{2}{|c|}{ All patients $(\mathbf{N}=\mathbf{7 5 0})$} \\
\hline & $\begin{array}{l}\text { Hazard ratio }(95 \% \\
\text { Confidence interval) }\end{array}$ & $P$ value \\
\hline Male sex & $1.34(1.07-1.66)$ & .01 \\
\hline IABP use* & $1.42(1.16-1.73)$ & $<.001$ \\
\hline Peripheral vascular disease & $1.62(1.34-1.97)$ & $<.001$ \\
\hline $\begin{array}{l}\text { NYHA functional class } \\
\text { IV }+ \text { age }<70 \mathrm{y}^{\dagger}\end{array}$ & $1.22(0.93-1.59)$ & .143 \\
\hline $\begin{array}{l}\text { NYHA functional class I- } \\
\quad \text { III }+ \text { age } \geq 70 \mathrm{y} \dagger\end{array}$ & $1.88(1.48-2.40)$ & $<.001$ \\
\hline $\begin{array}{l}\text { NYHA functional class } \\
\qquad \mathrm{IV}+\text { age } \geq 70 \mathrm{y}^{\dagger}\end{array}$ & $2.25(1.76-2.86)$ & $<.001$ \\
\hline
\end{tabular}

TABLE E3. Multivariable predictors of late all-cause mortality among all patients accounting for surgery type

\begin{tabular}{|c|c|c|c|c|c|c|}
\hline \multirow[b]{2}{*}{ Variable } & \multicolumn{2}{|c|}{ Controlling for CABG* } & \multicolumn{2}{|c|}{ Controlling for AVS $\dagger$} & \multicolumn{2}{|c|}{ Controlling for MVS $\mathbf{S}_{\ddagger}$} \\
\hline & HR $(95 \%$ CI) & $P$ value & HR $(95 \%$ CI) & $\overline{P \text { value }}$ & HR $(95 \%$ CI) & $\overline{P \text { value }}$ \\
\hline Older age $\S$ & $1.16(1.16-1.22)$ & $<.001$ & $1.16(1.10-1.22)$ & $<.001$ & $1.16(1.16-1.22)$ & $<.001$ \\
\hline Male sex & $1.24(1.02-1.52)$ & .035 & $1.23(1.01-1.51)$ & .041 & $1.23(1.00-1.50)$ & .047 \\
\hline NYHA functional class IV & $1.27(1.08-1.48)$ & .004 & $1.25(1.07-1.46)$ & .006 & $1.25(1.06-1.46)$ & .006 \\
\hline IABP use & $1.42(1.19-1.69)$ & $<.001$ & $1.40(1.17-1.67)$ & $<.001$ & $1.39(1.16-1.66)$ & $<.001$ \\
\hline PVD & $1.59(1.33-1.89)$ & $<.001$ & $1.56(1.31-1.85)$ & $<.001$ & $1.55(1.30-1.84)$ & $<.001$ \\
\hline Prior surgery & $1.48(1.19-1.69)$ & $<.001$ & $1.56(1.27-1.91)$ & $<.001$ & $1.59(1.29-1.95)$ & $<.001$ \\
\hline Surgery type & $0.83(0.67-1.02)^{*}$ & .080 & $1.08(0.91-1.28) \dagger$ & .383 & $0.98(0.78-1.22) \ddagger$ & .849 \\
\hline
\end{tabular}

$C A B G$, Coronary artery bypass grafting; $A V S$, aortic valve surgery; $M V S$, mitral valve surgery; $H R$, hazard ratio; $C I$, confidence interval; NYHA, New York Heart Association; $I A B P$, intra-aortic balloon pump; $P V D$, peripheral vascular disease. *Multivariable Cox model with CABG forced as covariate. $\dagger$ Multivariable Cox model with AVS forced as covariate. $\ddagger$ Multivariable Cox model with MVS forced as covariate. $\S$ Age increase by 5 -year increments. 